\title{
Kinerja Spectrum Sensing dengan Metode Matched Filter Detector pada Radio Kognitif
}

\author{
BAYU ANGGA $S^{1}$, DWI ARYANTA ${ }^{1}$, NASRULLAH ARMI ${ }^{2}$ \\ 1. Teknik Elektro Institut Teknologi Nasional \\ 2. Lembaga Ilmu Pengetahuan Indonesia \\ Email:ps_bayu@yahoo.com
}

\begin{abstract}
ABSTRAK
Evolusi sistem nirkabel dan teknologi saat ini telah membuat dampak besar pada masyarakat. Namun, disaat yang sama pengelolaan dan pemanfaatan kelangkaan spektrum tidak efisien. Radio kognitif adalah paradigma baru dalam merancang sistem komunikasi nirkabel yang bertujuan untuk meningkatkan pemanfaatan spektrum frekuensi radio (RF) dan mengurangi seminimal mungkin kelangkaan spektrum. Spectrum sensing adalah langkah utama yang akan memungkinkan jaringan radio kognitif, yaitu untuk menentukan status spektrum dan aktivitas pengguna utama secara berkala, dengan menggunakan metode matched filter detector dan energy detector sebagai pembandingnya. Hasil dari kinerja spectrum sensing berdasarkan simulasi, menunjukan kinerja matched filter detector membutuhkan SNR = $15 d B$ untuk mencapai probability detection ( $P d$ ) sebesar $100 \%$, dengan probability false alarm sebesar 0,01, sedangkan energy detector hanya membutuhkan SNR =14,2 dB. Secara keseluruhan untuk deteksi sinyal yang optimal kinerja matched filter detector tidak lebih baik dibanding kinerja energy detector.
\end{abstract}

Kata kunci: spectrum sensing, radio kognitif, probability detection, matched filter detector, energy detector.

\begin{abstract}
The evolution of wireless systems and current technology has made a huge impact on society. However, at the same time the management and utilization of spectrum scarcity is not efficient. Cognitive Radio is a new paradigm in designing wireless communication system that aims to improve the utilization of the radio frequency spectrum (RF) and reduce to a minimum the scarcity of spectrum. Spectrum sensing is a major step that will allow the cognitive radio networks, namely to determine the status of the spectrum and activity of the primary user at regular intervals, using the method of matched filter detector and energy detector as a comparison. The results of the performance spectrum sensing based on simulations, indicates the performance matched filter detector requires $S N R=15 d B$ to achieve detection probability $(P d)$ of $100 \%$, with a probability of false alarm of 0.01 , whereas energy detector only requires $S N R=14.2 \mathrm{~dB}$. As a whole for optimum signal detection performance of matched filter detector is not better than the performance of energy detector.
\end{abstract}

Keywords: spectrum sensing, cognitive radio, probability detection, matched filter detector, energy detector. 


\section{PENDAHULUAN}

Pada saat ini evolusi sistem nirkabel dan teknologi telah membuat dampak besar pada masyarakat. Namun, disaat yang sama telah menyebabkan kelangkaan band frekuensi untuk layanan baru. Hal ini menjadi suatu keharusan untuk pengelolaan spektrum yang efisien, Komisi Komunikasi Federal (FCC) menerbitkan pada laporan pengelolaan dan pemanfaatan spektrum, yang mengungkapkan bahwa alokasi spektrum sangat kurang dimanfaatkan. Sebuah studi oleh Spectrum Policy Task Force (SPTF), Federal Communication Commission (FCC) telah menunjukkan bahwa beberapa frekuensi band lisensi sering digunakan oleh sistem di lokasi tertentu dan pada waktu tertentu, tetapi bahwa ada juga banyak frekuensi band yang hanya sebagian digunakan atau sebagian besar kosong. Sebagian besar negara, spektrum band yang dialokasikan untuk jaringan selular mencapai pemanfaatan tertinggi selama jam kerja, tetapi sebagian besar tidak digunakan pada tengah malam sampai pagi. Radio kognitif adalah paradigma baru dalam merancang sistem komunikasi nirkabel yang bertujuan untuk meningkatkan pemanfaatan spektrum frekuensi radio (RF). Berdasarkan penelitian Yucek, T. and H. Arslan (Yucek dan Arslan, 2009), radio kognitif didasarkan pada konsep perangkat lunak radio dan menyediakan teknik untuk spectrum sensing, pengelolaan spektrum, dan akses spektrum tanpa izin untuk pengguna sekunder ketika pengguna utama tidak memanfaatkan spektrum. Fungsi dari radio kognitif adalah untuk mendukung akses spektrum dinamis yang cerdas dan efisien. Oleh karena itu, spectrum sensing dapat diandalkan dalam teknologi radio kognitif. metode pada spectrum sensing yang digunakan adalah matched filter detector dan energy detector.

Menurut penelitian Weifang Wang (Wang, 2009) Matched filter detector merupakan metode yang optimal karena membutuhkan pengetahuan tentang fitur sinyal pengguna utama seperti jenis modulasi, operasi frekuensi, bandwidth, bentuk pulsa, dan format frame. Primary user (PU) atau pengguna utama adalah alat komunikasi (device) yang memiliki sebuah frekuensi yang sudah dialokasikan. Secondary user (SU) atau pengguna sekunder adalah alat komunikasi (device) yang dapat mengakses sebuah frekuensi berlisensi untuk dapat melakukan proses komunikasi yang disebut dengan radio kognitif.

Pada tahun 2013 telah dilakukan penelitian tentang "I3S : Intelligent spectrum sensing scheme for cognitive radio networks" oleh Ejaz Waleed, Hasan Najam, Lee Seok dan Kim Hyung Seok (Waleed, Najam, Seok, dan Hyung Seok, 2013), berdasarkan parameter probability detection dan signal to noise ratio (SNR), dengan menggunakan model system I3S, bahwa gabungan metode energy detection dengan cyclostationary feature detector memiliki performa kinerja yang optimal. karena metode energy detection tidak perlu mengetahui jenis sinyal (jenis modulasi atau jenis sinyal pembawanya) dari primary user (PU) dan cyclostationary feature detector perlu mengetahui jenis sinyal PU. Berdasarkan beberapa hal tersebut, pada penelitian ini diambil judul "Kinerja spectrum sensing dengan Metode Matched Filter Detector pada Radio kognitif".

\section{METODOLOGI PENELITIAN}

\subsection{Sistem Kerja}

Pada tahap ini dalam melakukan simulasi terlebih dahulu dilakukan perencanaan terhadap apa yang akan disimulasikan serta menentukan parameter - parameter apa saja yang akan menjadi acuan. Hasil simulasi yang didapatkan akan ditampilkan dalam grafik dan dibandingkan untuk kemudian dilakukan analisa, seperti ditunjukkan pada gambar 1. 


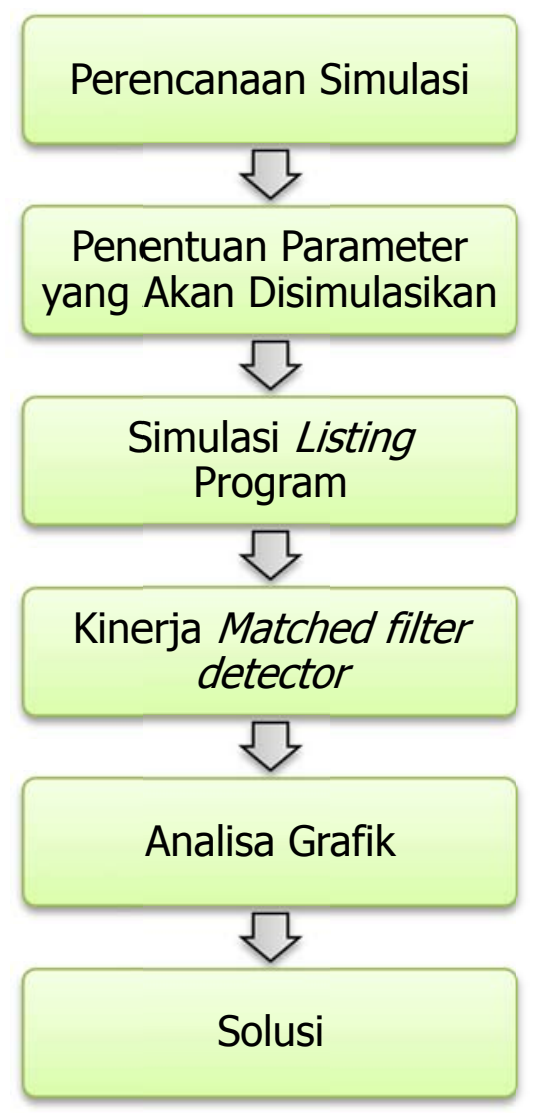

Gambar 1. Sistem Kerja

Gambar 1 menunjukkan sistem kerja simulasi, dimana pada perencanaan simulasi akan membandingkan probability detection (Pd) terhadap SNR dan tingkat probability false alarm (Pf) pada matched filter detector dengan energy detector sebagai pembanding. Parameter yang digunakan untuk memenuhi kriteria atau persyaratan kehandalan kinerja sebuah sinyal dalam melakukan sensing adalah probability detection (Pd), probability false alarm (Pf) dan signal to noise ratio (SNR). Probability detection (Pd) adalah probability yang memutuskan bahwa ada sinyal pengguna utama sementara sinyal pengguna utama memang benar-benar ada atau kemungkinan sinyal terdeteksi. Sedangkan probability false alarm (Pf) adalah probability yang memutuskan sinyal pengguna utama ada sementara sebenarnya sinyal pengguna utama tidak ada atau kemungkinan sinyal alarm palsu (probability false alarm (Pf)).

\subsection{Diagram Alir Simulas}

Diagram alir simulasi menunjukkan proses kinerja spectrum sensing menggunakan metode matched filter detector yang akan digambarkan dalam bentuk flowchart, seperti ditunjukkan pada gambar 2. 


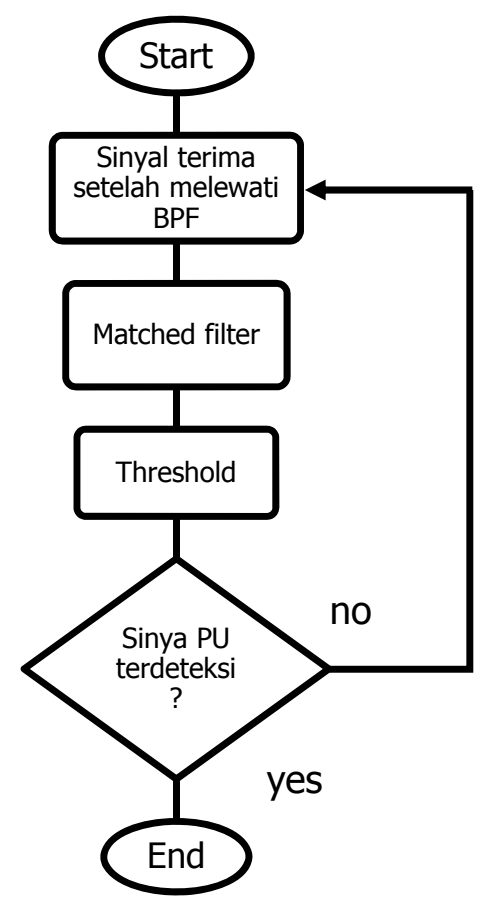

Gambar 2. Flowchart Matched Filter Detector

Dilihat flowchart pada gambar 2, hal yang pertama dilakukan untuk memulai simulasi program adalah menentukan sinyal yang diterima, dimana sinyal yang akan diterima adalah sinyal + noise. Untuk menentukan nilai sinyal dan noise, terlebih dahulu signal power dan noise power harus diketahui berdasarkan sample point, psudorandom generator dan sinyal to noise ratio (SNR). Dengan demikian sinyal yang diterima dapat ditentukan. Sinyal yang terima berupa sinyal digital kemudian melewati matched filter, hasil keluaran dari matched filter misalkan sama dengan z. Maka nilai z akan dibandingkan dengan threshold untuk menentukan deteksi pengguna utama ada atau tidak.

Pada simulasi ini untuk kinerja matched filter detector akan membandingkan nilai Pd dan Pf berdasarkan nilai SNR yang berbeda dari nilai terendah sampai tertinggi dalam satu grafik. Untuk kinerja matched filter detector versus energy detector, akan membandingkan nilai Pd dan Pf berdasarkan nilai SNR yang berbeda tiap grafiknya. Untuk melihat perbandingan antara Pd dan Pfa dalam grafik, kita dapat plot fungsi rocsnr. Untuk kinerja matched filter detector versus energy detector pada $\mathrm{Pf}=0,01$, akan membandingkan nilai probability detection (Pd) terhadap nilai SNR dengan mengatur tingkat probability false alarm (Pf) yang telah ditentukan sebelumnya. Hasil simulasi berupa gambar grafik dengan plot pada matlab menggunakan fungsi rocpfa.

Pada analisa grafik akan membandingkan probability detection (Pd) dengan probability false alarm (Pf) terhadap nilai SNR secara menyeluruh pada simulasi kinerja spectrum sensing. Dari hasil analisa grafik dapat menentukan kesimpulan dan solusi pada simulasi kinerja spectrum sensing, dimana simulasi metode matched filter detector akan dibandingkan dengan energy detector untuk menentukan mana yang lebih baik agar kinerja spectrum sensing optimal. 


\section{HASI L DAN PEMBAHASAN}

\subsection{Kinerja Matched Filter Detector berdasarkan beberapa nilai SNR.}

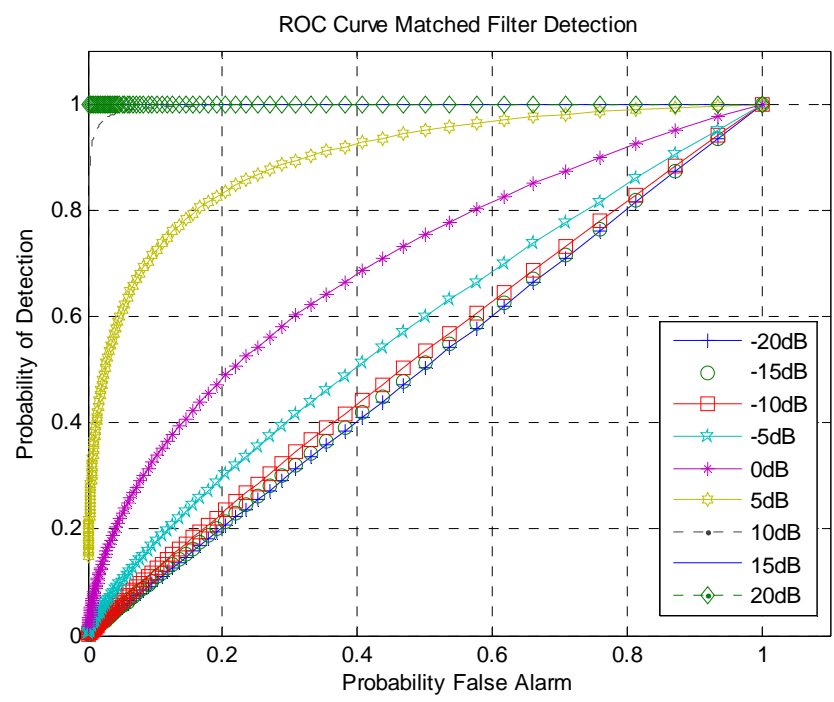

Gambar 3. Kinerja Matched Filter Detector

Gambar 3 menunjukkan kinerja dari matched filter detector yang sangat dipengaruhi oleh besarnya nilai SNR. Sebagai contoh perbandingan, dapat diambil grafik dengan nilai SNR = 0 $\mathrm{dB}$ dan grafik dengan nilai SNR $=10 \mathrm{~dB}$. Grafik dengan nilai SNR $=0 \mathrm{~dB}$ untuk mencapai nilai probability of detection sebesar $60 \%$, membutuhkan probability of false alarm sebesar 0,3 . Sedangkan grafik dengan nilai SNR $=10 \mathrm{~dB}$, untuk mencapai probability of detection sebesar $80 \%$, membutuhkan probability of false alarm sebesar 0 . Pada grafik dengan nilai SNR = $15 \mathrm{~dB}$ untuk mencapai nilai probability of detection sebesar $99 \%$, membutuhkan probability of false alarm sebesar 0,001. Dari hasil pembacaan grafik tersebut dapat diketahui bahwa kinerja matched filter detector untuk nilai SNR $=10 \mathrm{~dB}$ jauh lebih baik dari nilai $\mathrm{SNR}=0 \mathrm{~dB}$. Karena untuk kinerja matched filter detector dengan $\mathrm{SNR}=10 \mathrm{~dB}$, kemungkinan probability of false alarm jauh lebih kecil dibanding dengan SNR $=0 \mathrm{~dB}$ untuk probability of detection tertentu. Sehingga dapat disimpulkan bahwa semakin tinggi nilai SNR dari matched filter detector maka kinerjanya akan semakin meningkat dengan probability of false alarm serendah mungkin.

\subsection{Kinerja Matched Filter Detector dengan Energy Detector berdasarkan nilai} SNR.

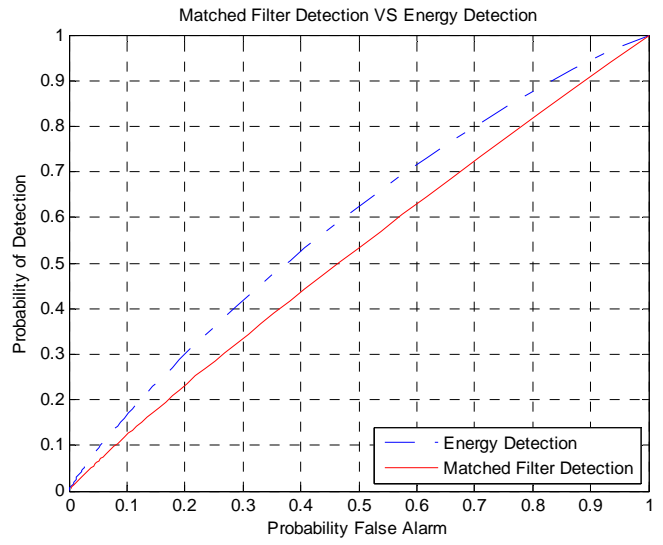

Gambar 4. Pd Untuk SNR=-10 dB

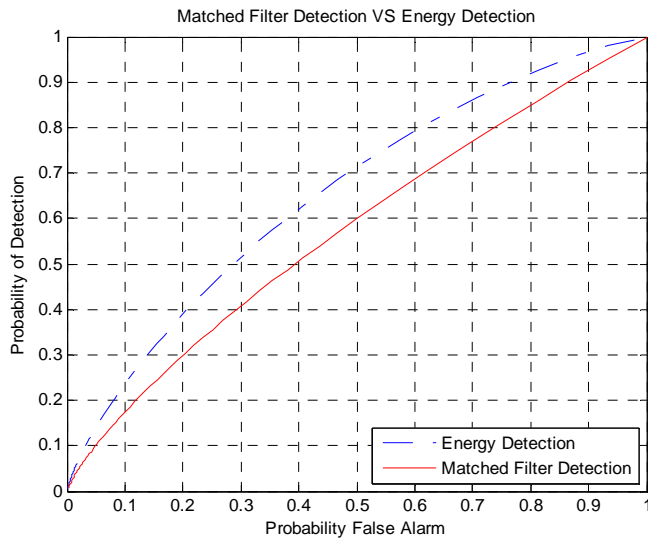

Gambar 5. Pd Untuk SNR=-5 dB 


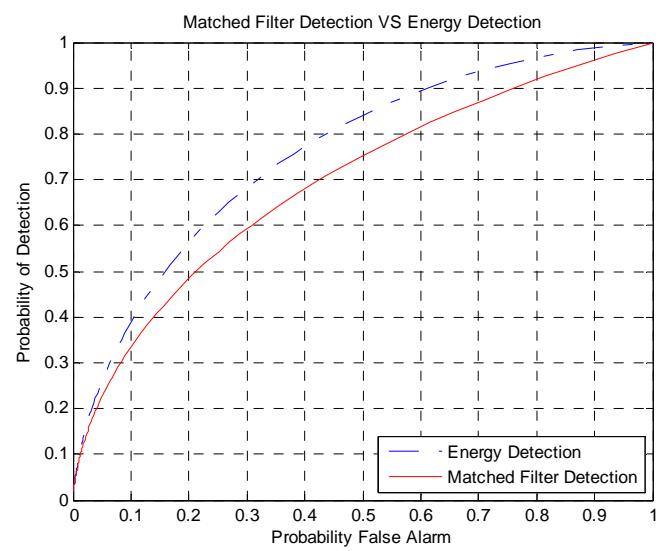

Gambar 6. Pd Untuk SNR=0 dB

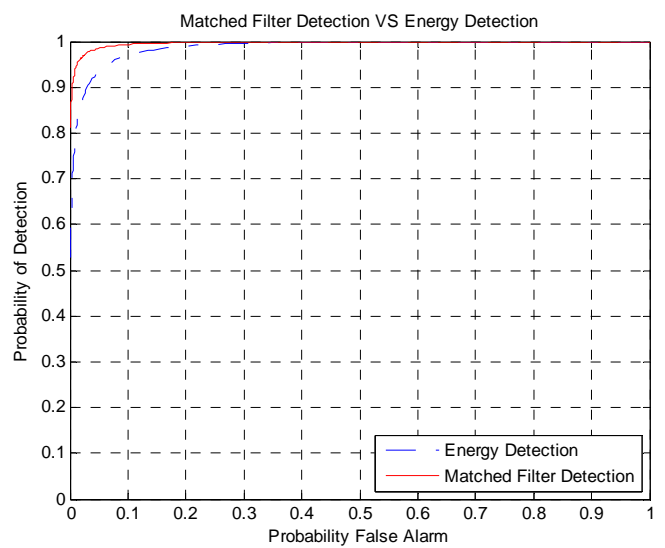

Gambar 8. Pd Untuk SNR=10 dB

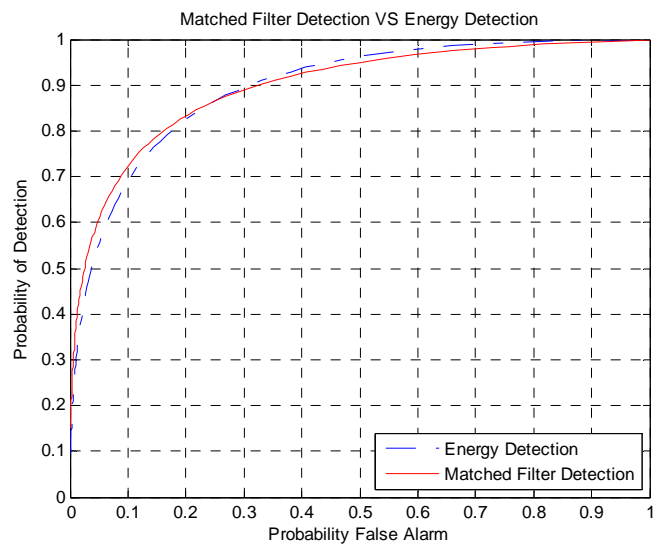

Gambar 7. Pd Untuk SNR $=5 \mathrm{~dB}$

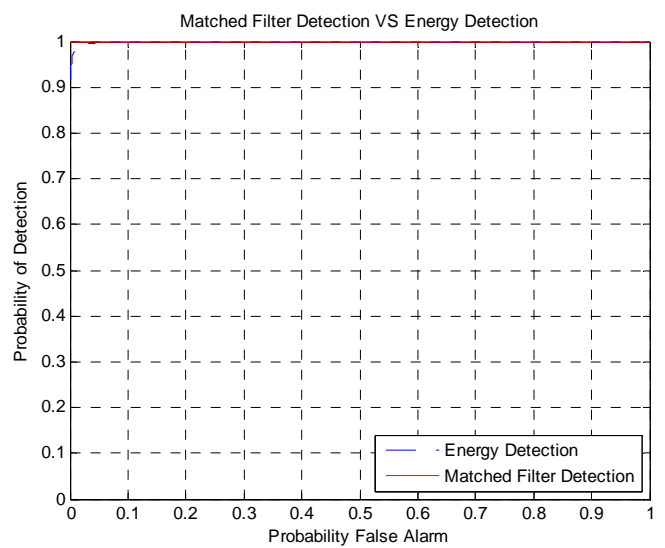

Gambar 9. Pd Untuk SNR=13 dB

Dari gambar 4 sampai dengan gambar 6, dapat diketahui bahwa kinerja dari energy detector lebih baik dibandingkan dengan kinerja matched filter detector. Sebagai contoh dapat dilihat pada grafik dengan nilai SNR $=-10 \mathrm{~dB}$ dan nilai SNR $=0 \mathrm{~dB}$, yang ditunjukkan pada gambar 4 dan gambar 6 . Untuk grafik dengan nilai SNR $=-10 \mathrm{~dB}$, kinerja matched filter detector untuk probability of false alarm (Pf) sebesar 0,2, mencapai probability of detection (Pd) sebesar $21 \%$, sedangkan kinerja energy detector mencapai probability of detection $(\mathrm{Pd})$ sebesar $25 \%$. Untuk nilai SNR $=0 \mathrm{~dB}$, kinerja matched filter detector dengan probability of false alarm (Pf) sebesar 0,2, mencapai probability of detection (Pd) sebesar 48\%, sedangkan kinerja energy detector mencapai probability of detection (Pd) sebesar $56 \%$. Hal tersebut telah menunjukkan bahwa kinerja energy detector lebih baik dari kinerja matched filter detector pada SNR kurang dari $0 \mathrm{~dB}$. Pada gambar 7 sampai dengan gambar 9 terjadi perubahan yang signifikan, matched filter detector memiliki kinerja yang lebih baik dari energy detector. Pada gambar 7 saat probability of false alarm (Pf) sebesar 0,1 , kinerja matched filter detector mencapai probability of detection (Pd) sebesar $73 \%$, sedangkan kinerja energy detector mencapai probability of detection (Pd) sebesar $70 \%$. Pada gambar 8 saat probability of false alarm (Pf) sebesar 0,1 , kinerja matched filter detector mencapai probability of detection (Pd) sebesar $98 \%$, sedangkan kinerja energy detector mencapai probability of detection $(\mathrm{Pd})$ sebesar $95 \%$. Hal tersebut telah menunjukkan bahwa kinerja matched filter detector lebih baik dari kinerja energy detector, pada SNR lebih dari $5 \mathrm{~dB}$ dengan probability of false alarm (Pf) tertentu. Dari perbandingan tersebut maka dapat 
disimpulkan bahwa kinerja dari matched filter detector tidak selalu lebih baik dari kinerja dari energy detector. Karena kinerja matched filter detector bekerja optimal pada SNR yang tinggi, dibandingkan dengan kinerja energy detector yang bekerja optimal pada SNR yang rendah.

\subsection{Kinerja Matched Filter Detector dengan Energy Detector berdasarkan Probability False Alarm (Pf).}

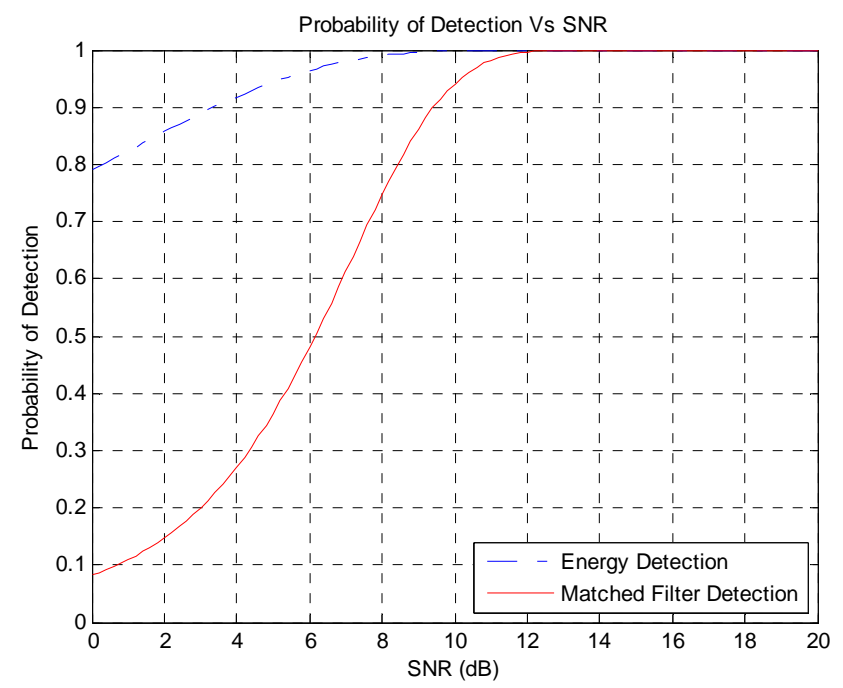

\section{Gambar 10. Probability Detection (Pd) Untuk Pf = 0,01}

Pada gambar 10 dapat diketahui bahwa kinerja matched filter detector tidak lebih baik dari kinerja energy detector. Dapat dilihat pada grafik dengan nilai SNR $=9 \mathrm{~dB}$, kinerja matched filter detector mencapai probability of detection (pd) sebesar $86,1 \%$, sedangkan kinerja energy detector sudah mencapai 99,56\%. kemudian untuk grafik dengan nilai SNR $=14,2$ $\mathrm{dB}$, kinerja matched filter detector mencapai probability of detection (pd) sebesar $99,99 \%$, sedangkan kinerja energy detector sudah mencapai 100\%. Pada kinerja matched filter detector untuk mencapai probability detection (Pd) 100\%, memerlukan SNR $=15 \mathrm{~dB}$. Hal tersebut dapat disimpulkan bahwa kinerja energy detector lebih baik dari kinerja matched filter detector, karena kinerja energy detector bekerja optimal pada SNR $\geq 14,2 \mathrm{~dB}$, sedangkan kinerja matched filter detector bekerja optimal pada SNR $\geq 15 \mathrm{~dB}$.

\section{KESI MPULAN DAN SARAN}

\subsection{Kesimpulan}

Berdasarkan pada analisis data hasil simulasi pada bab sebelumnya, maka dapat diperoleh kesimpulan sebagai berikut:

1. Kinerja matched filter detector bekerja optimal untuk mendeteksi sinyal pengguna utama yaitu pada SNR $=15 \mathrm{~dB}$ dengan probability false alarm kisaran sebesar 0,001.

2. Pada kondisi SNR $=5 \mathrm{~dB}$, kinerja matched filter detector tidak selalu lebih baik dibanding kinerja energy detector pada probability false alarm tertentu.

3. Pada kondisi SNR $=10 \mathrm{~dB}$ kinerja matched filter detector lebih baik dari kinerja energy detector, pada kisaran probability false alarm lebih dari 0,02.

4. Pada kondisi probability false alarm sebesar 0,01, kinerja matched filter detector tidak lebih baik dari kinerja energy detector, pada kisaran SNR kurang dari $15 \mathrm{~dB}$. 


\subsection{Saran}

Pada penelitian ini, pembahasan hanya dilakukan pada matched filter detector dan energy detector saja. Untuk selanjutnya disarankan dilakukan pembahasan pada metode spectrum sensing lainnya seperti cyclostationary feature detector.

\section{DAFTAR RUJ UKAN}

Yucek, T., and H. Arslan. (2009). A Survey of Spectrum Sensing Algorithms for Cognitive Radio Applications. IEEE Communications Surveys and Tutorials, Vol. 11, No. 1, pp: 116-130.

Weifang Wang (2009). Spectrum Sensing for Cognitive Radio. Third International Symposium on Intelligent Information Technology Application Workshops, pp: 410-412.

Subhedar, Mansi and Gajanan Birajdar (2011). Spectrum Sensing Techniques in Cognitive Radio Networks: a Survey. India: Department of Electronics and Telecommunication Engineering, SIES Graduate School of Technology, Navi Mumbai.

Verma, Pradeep Kumar. (2012). Performance analysis of Energy detection, Matched filter detection \& Cyclostationary feature detection Spectrum Sensing Techniques. India: Department of Electronics \& Communication Engineering, Jaipur National University.

Kim, Hyung Seok and Waleed Ejaz etc. (2013). I3S : Intelligent spectrum sensing scheme for cognitive radio networks. Republic of Korea : Department of Information \& Communication Engineering, Sejong University, Seoul. 